\title{
Understanding Tendons: Lessons from Transgenic Mouse Models
}

\author{
Manuel Delgado Caceres, ${ }^{1}$ Christian G. Pfeifer, ${ }^{1,2}$ and Denitsa Docheva ${ }^{1,3}$
}

Tendons and ligaments are connective tissues that have been comparatively less studied than muscle and cartilage/ bone, even though they are crucial for proper function of the musculoskeletal system. In tendon biology, considerable progress has been made in identifying tendon-specific genes (Scleraxis, Mohawk, and Tenomodulin) in the past decade. However, besides tendon function and the knowledge of a small number of important players in tendon biology, neither the ontogeny of the tenogenic lineage nor signaling cascades have been fully understood. This results in major drawbacks in treatment and repair options following tendon degeneration. In this review, we have systematically evaluated publications describing tendon-related genes, which were studied in depth and characterized by using knockout technologies and the subsequently generated transgenic mouse models (Tg) (knockout mice, KO). We report in a tabular manner, that from a total of 24 tendon-related genes, in 22 of the respective knockout mouse models, phenotypic changes were detected. Additionally, in some of the models it was described at which developmental stages these changes appeared and progressed. To summarize, only loss of Scleraxis and TGF $\beta$ signaling led to severe tendon developmental phenotypes, while mice deficient for various proteoglycans, Mohawk, EGR1 and 2, and Tenomodulin presented mild phenotypes. These data suggest that the tendon developmental system is well organized, orchestrated, and backed up; this is even more evident among the members of the proteoglycan family, where the compensatory effects are much clearer. In future, it will be of great importance to discover additional master tendon transcription factors and the genes that play crucial roles in tendon development. This would improve our understanding of the genetic makeup of tendons, and will increase the chances of generating tendon-specific drugs to advance overall treatment strategies.

Keywords: tendon and ligaments, tendon biology, mice models, knockout mice, transgenic technology, tendon phenotype

\section{Introduction}

Tendon development, critical factors and signaling cascades

$\mathrm{T}$ HE ESTABLISHMENT OF a proper musculoskeletal system involves the finely orchestrated development of muscle, cartilage, and tendon lineages emerging from the somitic mesoderm [1]. During embryonic development, muscle and cartilage (systems that are better understood and studied than tendon) arise from the myotome and sclerotome respectively, in response to signals emitted from neighboring tissues. The tendon lineage is formed within the dorsolateral sclerotome, adjacent to and beneath the myotome, in a somite subdomain denominated as syndetome [1]. The ontogeny of the tenogenic lineage is not fully understood yet because of the absence of specific early tendon lineage markers.
To our knowledge, there are two stages related to tendon development. First, the emergence of precursors/progenitors based on their origin and localization and second, commitment and differentiation based on pivotal signaling cascades. With the identification of the beta helix-loop-helix transcription factor Scleraxis (Scx), an important and distinctive marker for early tendon development was found $[2,3]$. Schweitzer et al. reported the usage of Scx expression as a method for the identification of a pool of tendon progenitors in the mesenchyme subjacent to the ectoderm [3]. In mice, embryonic tendon and ligament development starts occurring between E9.5-E12.5 [4].

The main function of the axial tendon is to bond the muscles that are located along the spinal column to the vertebrae and transfer the generated force to the axial skeleton, providing spinal stability and range of movement

\footnotetext{
${ }^{1}$ Experimental Trauma Surgery, Department of Trauma Surgery, University Regensburg Medical Centre, Regensburg, Germany.

${ }^{2}$ Department of Trauma Surgery, University Regensburg Medical Centre, Regensburg, Germany.

${ }^{3}$ Department of Medical Biology, Medical University-Plovdiv, Plovdiv, Bulgaria.

(C) Manuel Delgado Caceres et al. 2018; Published by Mary Ann Liebert, Inc. This Open Access article is distributed under the terms of the Creative Commons License (http://creativecommons.org/licenses/by/4.0), which permits unrestricted use, distribution, and reproduction in any medium, provided the original work is properly cited.
} 
[4]. Axial tendon progenitors, which per definition are Scxexpressing cells, originate during embryonic development from the ventral compartment of emerging somites, more precisely, from the syndetome, one of the four somatic sub compartments [5-8].

Fibroblast growth factors (FGF) play an important role in chick and mouse embryos during axial tendon development (Fig. 1A). In mice, FGF signaling starts from the upper myotome resulting in the activation of the mitogen-activated protein kinase pathway, E26 transformation-specific sequence (Ets) transcription factors, Phosphatidylinositol-4-phosphate 5-kinase (Pea3) and Ezrin/radixin/moesin (Erm). Lastly, Scx and transcription factor Mohawk (Mkx) promote final tendon lineage commitment and differentiation; this is characterized by the expression of collagen type I, type XIV, and tenomodulin (Tnmd) $[1,9,10]$; Tnmd is to date, the best-known mature marker for tendons [11-13].
On the other side, ventral midline sonic hedgehog expression can solely activate Pax 1 , which consequently has a negative effect on Scx, hindering its induction in the sclerotome [10]. While signals coming from the myotome positively influence axial tendon development, signals derived from the sclerotome have an adverse effect. This starts with the expression of Sox9 and subsequent induction of Sox 5 and Sox6, which block Scx expression [10].

Progenitors of the limb tendons develop differently to the cells that give rise to axial tendons because they are not localized within a specific subdomain in the somite but rather around the lateral plate mesoderm [7,14]. Limb tendon progenitor cells are intermingled with migrating myoblasts in ventral and dorsal parts of the limb bud $[8,15]$. During limb development, Scx-positive tendon progenitors are induced by ectodermal signals and constrained by bone morphogenetic protein [10] in the limbs and position themselves
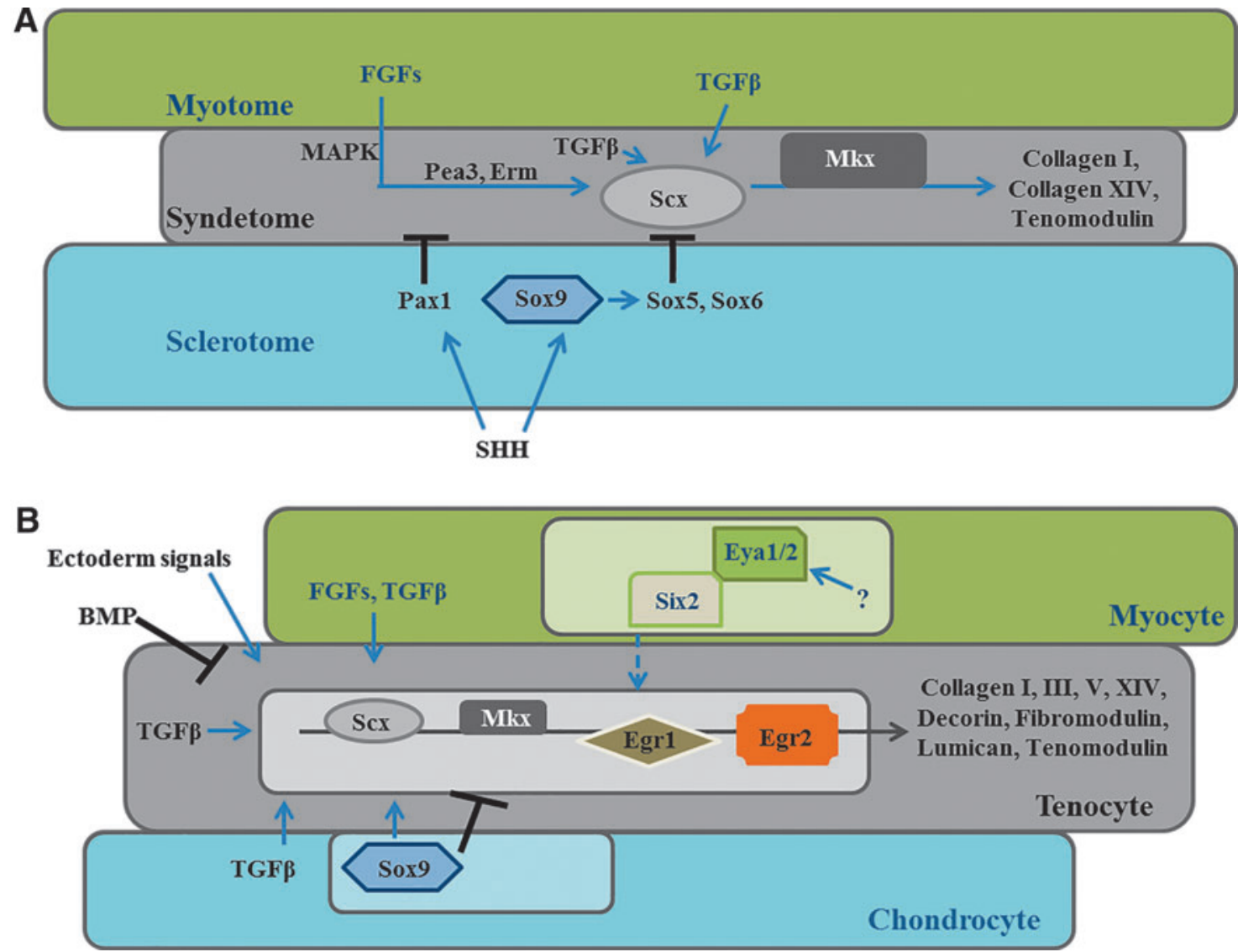

FIG. 1. Development of axial and limb tendons during embryogenesis. (A) Axial tendon differentiation starts with upcoming FGF signaling from myotome. Signals from the sclerotome, for example, Sox9 (activated by SHH) have a negative effect on Scx induction blocking its expression. Moreover, TGF $\beta$ signaling influences Scx and Mkx expression promoting axial tendon differentiation and the activation of extracellular matrix proteins such as collagen I, collagen XIV, tenomodulin, and others. (B) Limb tendons are formed differently compared to axial tendons. Tendon limb progenitors are induced by ectodermal signals in the limbs and inhibited by BMP. Tendon progenitors position themselves between differentiating muscles and cartilage, condensate, and differentiate to form proper tendon tissue. Not only FGF but also TGF $\beta$ can induce limb tendons. Six 2 is highly expressed in forming limb tendon cells, but the role of Eya1/2 is still controversial (therefore indicated with?). As in the axial tendon development, Scx and Mkx play a pivotal role giving the starting impulse for limb tendon formation. Early growth response 1 and $2($ Egr1/2) transcription factors act as molecular sensors for mechanical signals guiding the final steps of tendon maturation and production of collagen I, III, V, XIV, proteoglycans (decorin, fibromodulin, lumican), and tenomodulin. Figure was adapted from [10]. BMP, bone morphogenetic protein; FGF, fibroblast growth factors; SHH, sonic hedgehog. 
between differentiating muscles and cartilage. Subsequently, they condense and finally differentiate to form distinct tendons [8] (Fig. 1B).

Not only FGF signaling has a pivotal role in regulating limb tendon differentiation, proteins from the TGF $\beta$ superfamily have been reported to be inducers of limb bud tendons [16-19] (Fig. 1B). It has been previously described that the disruption of TGF $\beta$ signal in double mutant $T g f \beta 2^{-/-}$, Tgf $\beta 3^{-/-}$mouse embryos leads to the loss of most tendons and ligaments in the limbs, trunk, tail, and head [20].

The close interaction between muscles and tendons during limb development [7,15,21] suggests that transcription factors such as Six homeobox 1 and $2($ Six 1/2) and EYA transcriptional coactivator and phosphatase 1 and 2 (Eya1/2) [22] might play an indirect role in tendon formation. However, Bonnin et al. showed using Sixl-deficient mice that this gene is neither expressed in tendons nor essential for tendon development [23]. Whole transcriptome expression profiling of mouse limb tendons using RNA-Seq. revealed no differential expression of Six1, while Six 2 was found to be highly expressed in forming limb tendon cells at E13.5 [24].

As in axial tendon development, Scx and Mkx play a crucial role, giving the initial impulse for limb tendon formation. In a second step, Early growth response 1 and 2 (Egr1/2) act as molecular sensors for mechanical signals [25] guiding and regulating collagen maturation and leading to final tendon differentiation [10,26-28].

The exact mechanisms triggering tenogenesis, which need to be finely orchestrated to guide progenitor cells to fully differentiated tendon cells, still remain elusive and worth further investigation since the whole process is dependent on various factors with different signaling cascades amongst the diverse cellular compartments.

\section{Tendon function, composition, and structure}

Tendons appear to be simply organized tissues with the main function of connecting muscles with bones transmitting the muscle-generated force, thus allowing joint movements [29,30]. Tendons, which could be compared to flexible strings, are primarily made of collagens and a minor fraction of elastin surrounded by a proteoglycan-rich matrix. Concerning the mechanical function, tendons can be classified as positional tendons, which are primarily loaded along their long axis permitting the interplay between muscles and bones [29,31] and energy storing tendons that are more elastic and extensible and when loaded, release the accumulated energy to improve the efficiency of movement [32].

The tendon extracellular matrix consists mainly of collagens (60-85\% of tissue's dry weight) [33], with type I being the most prominent one $(\sim 95 \%)$ and small amounts of type V, VI, XII, XIV, and XV [34,35]. The role of collagens within tendons has been well studied and characterized [36-38] but the noncollagenous part of the matrix consisting of proteoglycans like fibromodulin, lumican, biglycan, and decorin [39-41] requires more investigation. Recent advances in proteoglycans research will be discussed later.

Tendons are hierarchically organized structures with collagen fibrils as the smallest structural units; these are composed of parallel chains of collagen molecules bound together by covalent cross-links [30]. Fibrils aggregate gradually with other fibrils to form tube-like structures called fibers, which subsequently attach to other fibers and arrange themselves into bundles (collagen-rich fascicles). Collagen fascicles are aligned in the direction of force application [42] and are surrounded by thin layers of connective tissue known as endoand epitenon (tendon sheets), where nerves, blood vessels, and tendon stem/progenitor cells are situated [41]. Fully differentiated tendon cells (tenocytes) are localized between the collagen fibers [41].

\section{Power of Knockout Technologies}

Knockout/-in technologies are a powerful and indispensable tool to study gene functions in vivo. In 2007, the Nobel Committee for Physiology or Medicine awarded Drs. Capecchi, Evans, and Smithies with the Nobel Prize for their discoveries in the field. The identification and isolation of stem cells of the early mouse embryo, the proper cell culture conditions, and the reintroduction of the genetically modified cells into foster mice mothers was established by Martin J. Evans and Matthew Kaufmann in the early 80s [43]. Mario Capecchi and Oliver Smithies, working independently of each other, discovered the mechanism behind homologous recombination $[44,45]$, creating the fundamentals for the production of the first knockout mice $[46,47]$.

Due to the startling gene homology between mice and humans (99\%) [48], mouse knockout technology has great advantages for the understanding of human biology and disease [48-50]. The mouse, as an experimental model is fundamental in biomedical research, since its development, physiology, behavior, and diseases are similar to those in humans [49]. Additionally, mouse properties such as short life spans and high reproduction rates make it very suitable for low-cost genetic studies.

The most obvious approach to investigate a gene's function is by generating a knockout and to validate the outcome by analyzing the whole animal phenotype [51]. The capacity to manipulate and introduce specific DNA sequences (eg, genes) has been used for biomedical purposes for more than three decades [52]. Furthermore, with the introduction of CRISPR/Cas-9 and CRISPR/Cas-13 technologies, new and precise tools for genome engineering are now available [53,54].

There are two main methods for the generation of knockout mice: (i) Gene trapping [55,56] and (ii) gene targeting $[43,45]$. Gene trapping mutagenesis was first developed for the detection of different gene expression patterns [57] but it is now well established as random mutation technique. Gene targeting is based on homologous recombination and proper manipulation of embryonic stem cells (ES cells). This technique permits the insertion of genetic mutations into a mouse at a specific genomic locus and generates full gene knockout, point mutation, deletion/ insertion (indel), and others. [58]. In this review we will shortly describe options and techniques for the generation of mouse knockout models.

\section{Conventional knockout mouse model (constitutive)}

This biological model targets a gene, which will be constitutively inactivated and has therefore a major effect at all stages of development (Fig. 2A). The method is based on the inactivation of the gene of interest by the insertion of a null mutation into an essential coding region in a specific genetic locus [58]. The modified sequence is inserted into 
a targeting vector containing an antibiotic resistance gene between the homologous regions (eg, neomycin). This step will allow a subsequent selection for positively transfected ES cells [58-60].

The technique commonly used for transfection is electroporation, because of its high efficiency and stable DNA introduction [61]. ES cells containing the mutagenized DNA construct are inserted into blastocysts, which are finally transferred into pseudopregnant females for the production of chimeric mice [60]. Offspring from chimeric mice have to be screened for targeted mutation and inbred to generate homozygous knockout mice. The main disadvantage of a constitutive knockout system is the fact, that roughly onethird of the genes present in mammals $(\sim 8,000$ genes in mice) are essential. This means that the deletion of two copies of some genes may either lead to embryonic or postnatal lethality, or could activate a nonregulated expression of other compensatory genes [62].

\section{Tissue-specific knockout mice (conditional)}

An interesting and effective approach to circumvent embryonic lethality or compensatory mechanisms, is the generation of conditional knockout mice by the use of, for example, Cre/loxP- (Cre recombinase/loxP sites) [63] or Flp/FRT technology (Flp recombinase/FRT sites) [64,65]. A target gene can be specifically inactivated in defined tissue(s), while its expression stays unaffected in the rest of the body [58] (Fig. 2B). Of great benefit is the possibility to inactivate a particular gene in a predefined cell lineage or at certain stage of development (eg, in the tenogenic lineage, Scx) [66].

For the proper usage of the Cre-loxP recombination system two mouse strains are required: the first one, called the deleter mouse line (where the Cre-recombinase is expressed) and the second strain carries the targeted gene flanked by two loxP sites. When intercrossed, the resulting offspring carries both, Cre-recombinase and loxP-flanked ("floxed") target gene. In the cells, where the Cre gene is expressed and due to Cre-loxP site-dependent recombination deletion/ excision of targeted gene will occur [67].

The main disadvantage of this approach is the time taken to develop this model, since there is the need for an additional breeding steps with the tissue-specific deleter mouse line. Additionally, it has been reported that the efficiency of gene deletion differs depending not only on the age and sex of the transgenic animal but also on gene locus position and Cre activity $[68,69]$.

\section{A Wild type mouse}

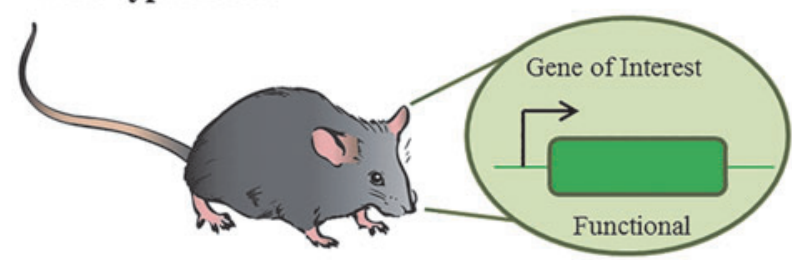

\section{Constitutive Knockout mouse}

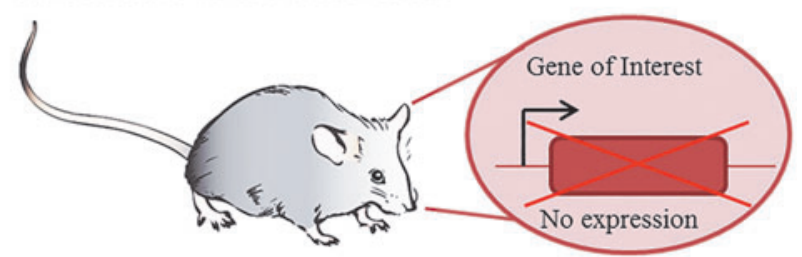

\section{B Tissue-specific Knockout mouse}

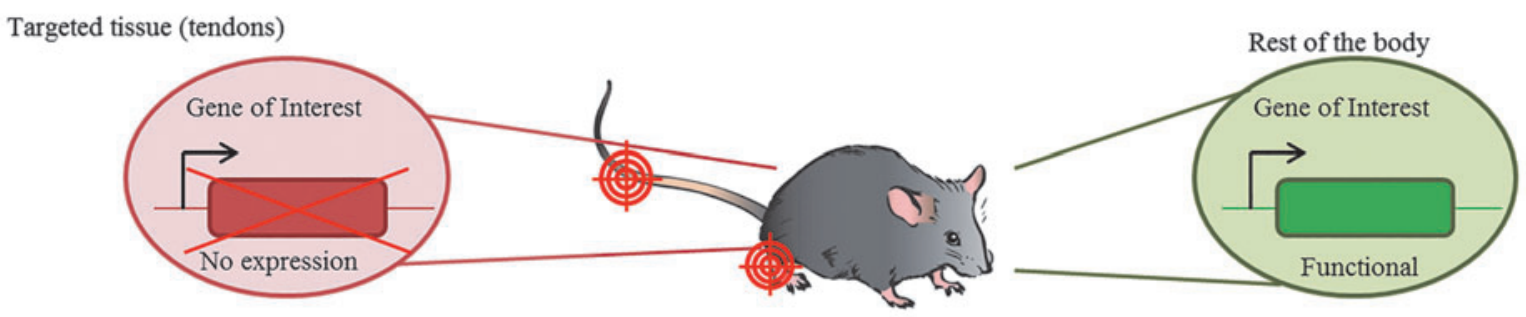

\section{Inducible Knockout mouse}

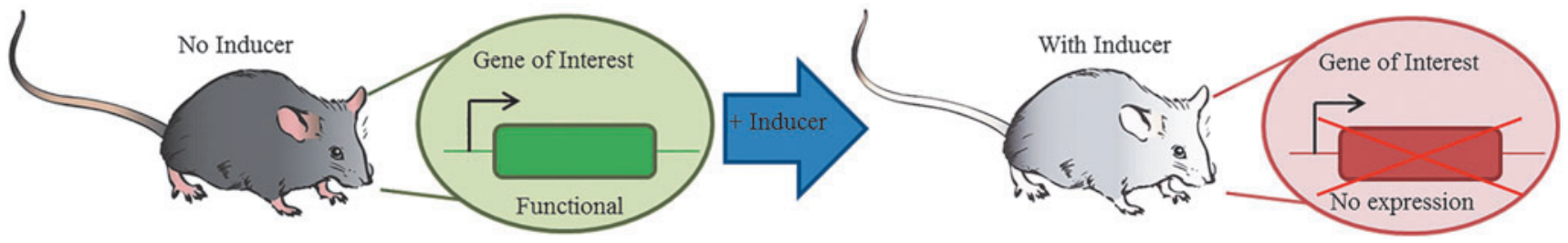

FIG. 2. Schematic representation of constitutive, conditional, and inducible knockout mouse models. (A) In a wild-type mouse, the GOI is functional. In a constitutive knockout mouse the GOI is not functional and therefore not expressed. The generated Tg-mouse might show phenotypic changes, depending on which gene has been knocked out. (B) In a tissuespecific knockout mouse the GOI is not functional in a specific tissue, while normal gene functionality is detected in the rest of the organism. In the cartoon the red targeted area illustrates that the gene is inactivated only in tendon tissues such as in the tail and Achilles tendons. (C) Inducible knockout systems allow the inactivation of a GOI by the addition of an inducer (in defined doses) at a given time point and within a specific tissue, before that, gene of interest is functional. Figure was adapted from [154-156]. GOI, gene of interest 


\section{Inducible knockout mouse models}

Inducible transgenic mouse models allow the activation/ inactivation of a target gene at a given time point and within a particular tissue. Before this, the gene of interest is either expressed or not (Fig. 2C). The first inducible system, based on tetracycline, called Tet-off and Tet-on system, was developed by Gossen and Bujard [70,71]. Other systems were later developed, including the tamoxifen system [72].

The inducible gene expression regulation is based on a bi-transgenic system and the estrogen receptor (ER) ligandbinding domain [73,74]. Transcription factors or recombinases can be genetically modified and subsequently be ligated into the mutated ligand-binding domain of the ER. Therefore, genes can be turned/switched on and off by administering triggering compounds [74]. The main advantage is that inactivation can be done in all cells of the body or in a tissuespecific manner. Conversely, the main disadvantage relays in the important role played by the inducer since it may generate complications in the phenotype.

\section{CRISPR-Cas technology}

This new technology takes advantage of precise genome engineering tools to increase the feasibility for the faster generation of transgenic mice models, which is of great importance for more in-depth study of the musculoskeletal system. Nelson et al. showed that in vivo genome editing improved muscle function in a Duchenne muscular dystrophy mouse model; Tabebordbar et al. and Suzuki et al. have also shown similar results [75-77]. The accessibility to this technology has increased rapidly in the last years and the simplicity of the system is its greatest advantage. Naturally, there are important issues that have to be taken into account while working with this tool [78].

The classical approach for the generation of knockouts is by injecting Cas9 mRNA and the single guide(s) RNA (sgRNA) directly into mouse embryos producing accurate edits into specific genomic loci. Mice that develop from the modified embryos have to be sequenced and/or genotyped to confirm that they carry the wanted mutation and bred to corroborate that a germline transmission is possible. The offspring can directly be crossed saving time and resources and eliminating the necessity of backcrossing.

\section{Translation and Relevance for Clinical Treatment}

To unveil critical mechanisms in tissue degeneration and regeneration, knockout or knock-in animal models of specific genes is of utmost importance. Small animals seem to be genetically very similar to human beings, a high number of genetic patterns and downstream mechanisms are comparable and preserved throughout evolution. Thus, genetically altered mouse models have already been used in the musculoskeletal field to uncover diseases and develop potential therapies for clinical use. For example, fibrodysplasia ossificans progressiva (FOP) is caused by a genetic variant in the glycine/serine activation domain of activing A type I receptor/activin-like kinase 2 (ACVR1/ALK2) and leads to lethal ossifications of soft tissues in the developing and growing human body $[79,80]$.
This gene mutation was mirrored in a knock-in mouse, which developed FOP and is therefore, now used for generation of specific therapies against this lethal disease [81]. Most recently, it was shown that depletion of mast cells in these mice leads to less severe heterotopic ossifications and minor dysplastic bone formation compared with untreated animals, paving the way for clinical translation [82]. As this example from bone formation disorder shows, genetically altered small animals are of great use for increasing insights into clinically relevant illnesses and may serve as a starting point for the development of clinically useful therapies.

A knockout mouse model of biglycan and fibromodulin, both of which are important contributors to tendon development and tendinous homeostasis, has shown heterotopic ossification of tendons [83]. Biglycan is a X-chromosome related small leucine-rich proteoglycan and due to its genetic location is underexpressed in $\mathrm{X}$-chromosome-deficient patients and overexpressed in multi-X-chromosome aberrations, such as Turner syndrome (X0) and Klinefelter syndrome $(\mathrm{XX}+)$ respectively. While Turner's syndrome is characterized by short stature, Klinefelter syndrome is characterized by tall stature [84].

However, single knockouts of biglycan only led to mild age-related osteopenia due to the lack of osteogenetic precursors [85]. Ultrastructural analysis of singly biglycan knockout mice showed disorganization of the collagen network in structural tissues, mimicking Ehlers-Danlos-like changes [86]. Interestingly, decorin (Dcn) was upregulated in these knockout mice, suggesting a compensation of biglycan loss on a molecular level [87] and further studies using a double biglycan/decorin knockout revealed severe osteopenia, overall reduced health status and infertility [86]. Furthermore, it was shown, that severity of tendon calcification is dependent on single vs. double knockout, age and biglycan vs. fibromodulin knockout [88].

Working groups studying tendon biology have suggested that, based on published data, tendon degeneration, growth, and regeneration have underlying multifactorial genetic contributors [85-89]. To gain insight in different genetic regulators and correlate those with clinical findings, both small animal gene knockout and clinically relevant studies have to be conducted. As stated before, experimental studies using transgenic animals and different models, such as functional performance [13], injury [90], and inflammation/ degeneration [91] should be stressed out.

An example of relevant experimental knockout studies was published by Dex et al., where the endurance running performance of Tenomodulin-deficient (Tnmd-KO) mice was analyzed [13]. Tnmd-KO mice have been previously described and showed a mild tendon but no developmental phenotype [11]. Tnmd deficiency led to significantly inferior running performance that worsened with training.

Using the same transgenic line, Lin et al. applied an Achilles tendon injury model to challenge the role of Tnmd in early tendon healing [90]. Detailed analysis showed a very different scar organization in the injury site of the $\mathrm{KO}$ tendons with an augmented adipocyte and blood vessel accumulation. This demonstrated that Tnmd is needed to prevent fat cells accumulation and fibrovascular scar formation, which subsequently have an impact in tendon functionality and healing [90]. 

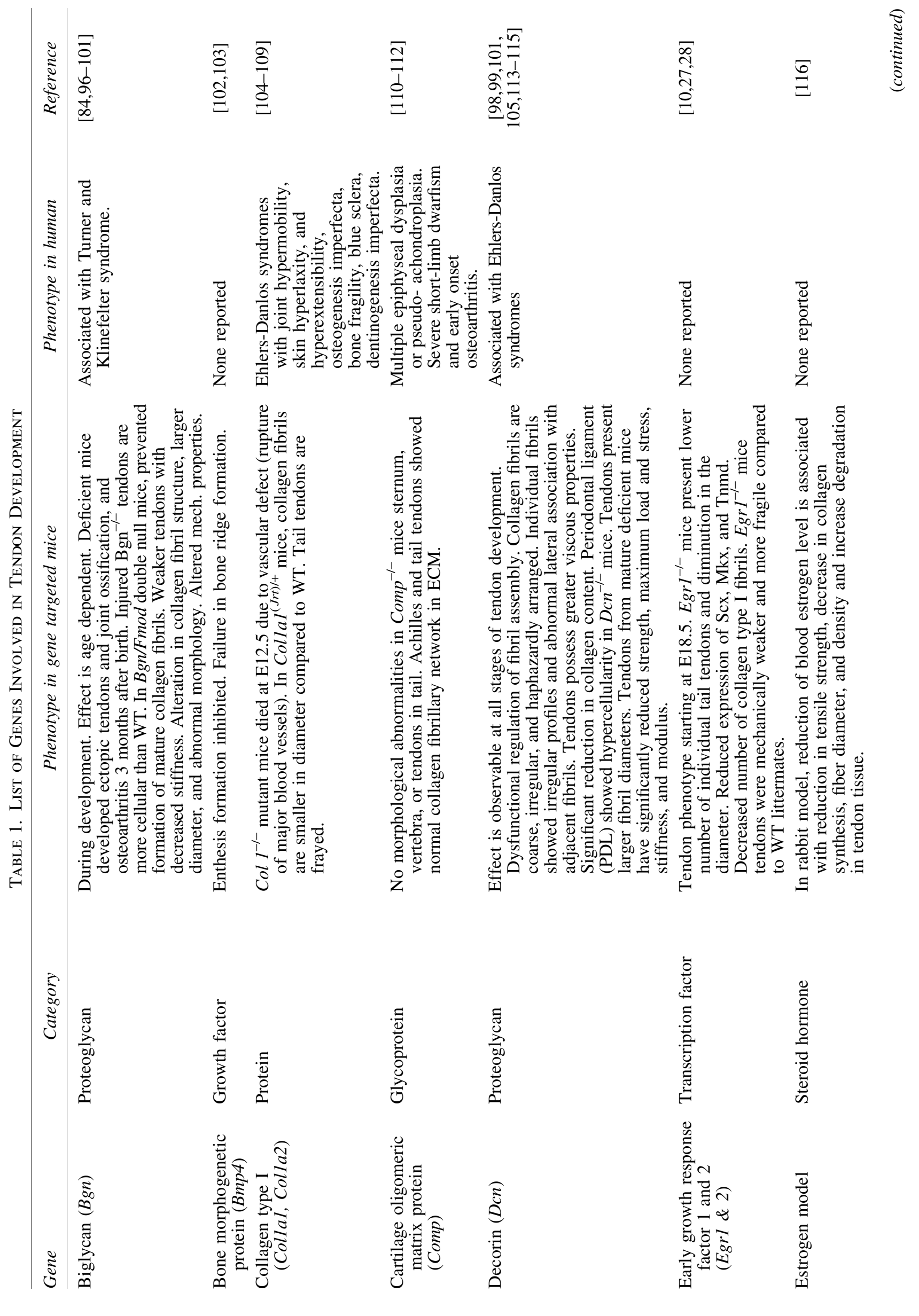


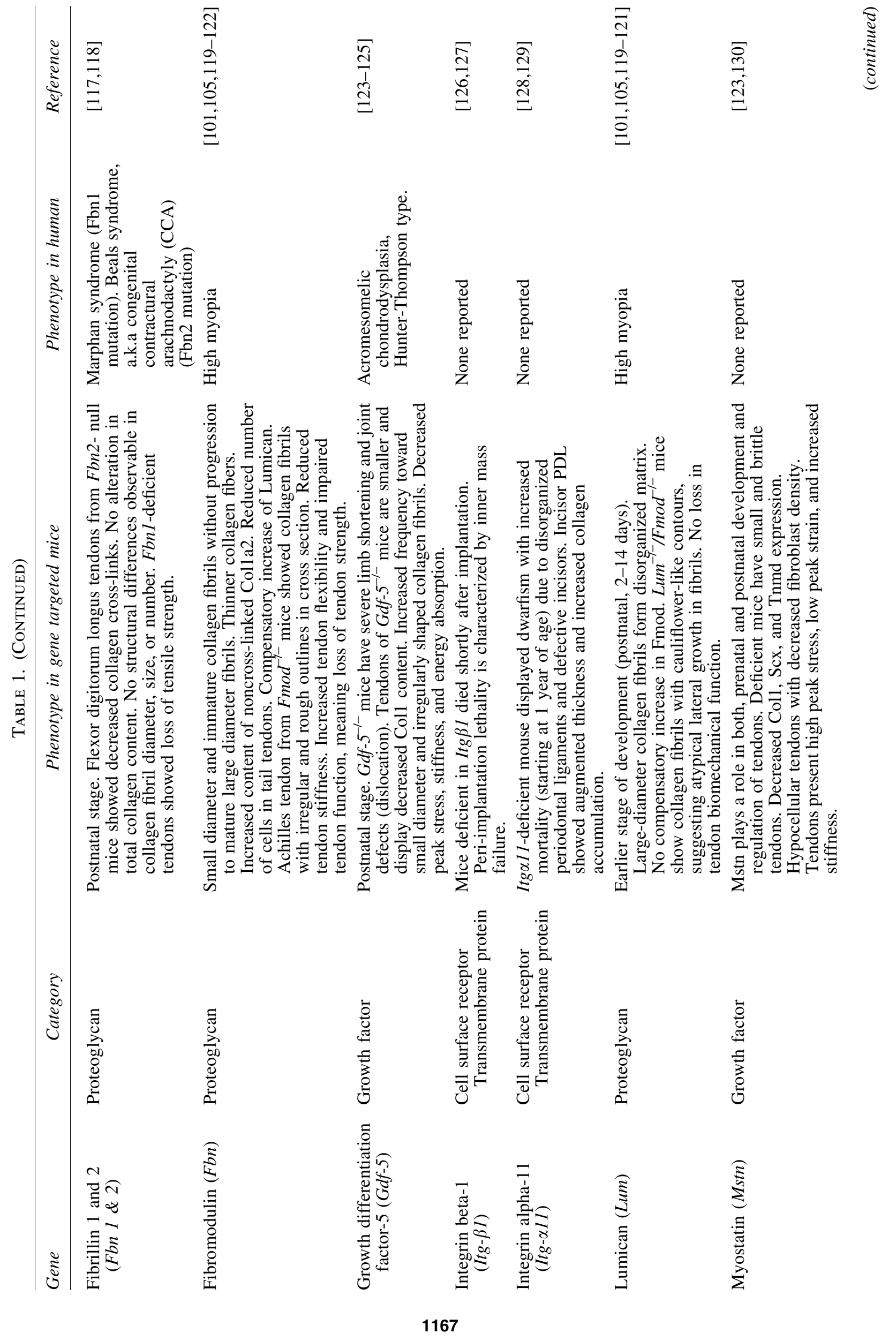




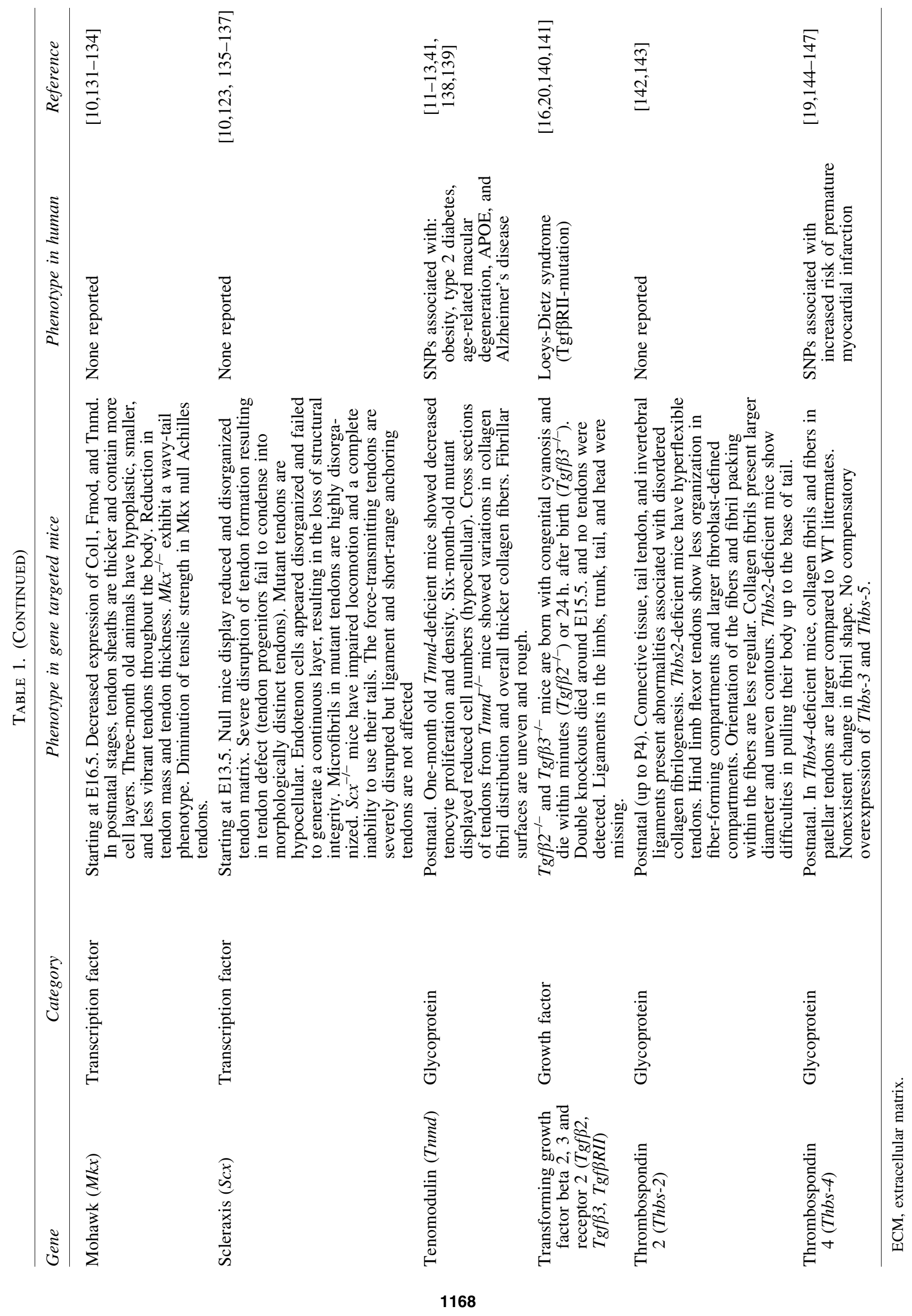


There are three different scenarios that might help to optimize the study and translation of animal models to the development of future clinical treatments. (i) Target a specific gene to see whether the generated phenotype mimics a human disease; (ii) find a human disease with the respective genetic mutation and generate a KO-mouse model to understand the mechanisms involved, and (iii) use transgenic mice with no developmental phenotype and challenge the system testing the above-mentioned models (performance, injury, and inflammation/degeneration).

Thus, genetic animal models will serve in the future to unveil contributors for tendon disorders and add to the development of clinically meaningful therapies whether in prevention of tendon degeneration and injuries or improving the speed and effectiveness of recovery of tendon ruptures.

\section{Genes Involved in Tendon Development}

Over the past 30 years, the usage of transgenic technologies has proved to be a very powerful and helpful tool for in-depth gene studies, not only by "loss-of-function" experiments but also by targeting a specific gene's overexpression. New tools and methods have supported a more detailed molecular analysis of tendons including the commitment, development, maturation, and consolidation of progenitor cells into fully differentiated tendon cells.

We have screened for a large number of tendon-related genes, which have been previously studied using corresponding gene-deficient mice (Table 1). We have summarized and classified diverse transgenic mice strains that have been used to analyze specific gene's function and have been of great help to understand tendon biology (Table 2). Moreover, we have described meticulously, if a phenotype is evident in constitutive, conditional, or inducible knockout mice, especially regarding tendon tissue morphology, structure, or mechanical function. One of the first descriptions made in the table is the time point by which the phenotype is noticeable; we specify how the tissue affected is organized, which changes are present at a cellular and ultra-microscopic level, and whether the biomechanics of the tendons were compromised.

\section{Open Questions, Concluding Remarks, and Future Perspectives}

The goal of this review was to transmit in a comprehensive manner how important basic research has been and still is for the appropriate understanding of tendon tissue, its biology, development, and function. It is remarkable that even though $\sim 45 \%$ of all musculoskeletal injuries in the United States each year are due to tendons and ligaments $[89,92]$ very little attention has been given to the study of these tissues. The shortage of unambiguous tendon markers and the absence of suitable cell lines has been a constant issue impeding the breakthrough needed for understanding the mechanisms behind tendon development, maintenance, and repair. Basic research using small animal models (mouse and rat models) and knockout technologies has proven to be a success for the study of single genes, their function and role within a specific system.

On one side, the Cre/loxP- and Flp/FRT- technologies represent a valuable and powerful tool for the study of single genes in a controlled context and tissue that needs to be further investigated. Initially, the expression of Cre and Flp was not expected to be harmful because it was thought that mouse genome would not contain endogenous loxP or FRT sites [93] but Thyagarajan et al. showed in vitro, that sequences from human and mouse genomes appeared to be different from loxP and could support Cre-mediated recombination, thus, resulting in reduced specificity [94].

The possibility of combining ScxCre transgenic mouse line [66] with floxed genes, or the generation of new Cre-lines under the control of known tendon-related genes (Tenomodulin-Cre, Mohawk-Cre, Collagen type I-Cre, and Thrombospondin-Cre) would contribute immensely to augment our knowledge on the field and would allow us to obtain more information about signaling pathways, and upstream and downstream molecular regulators. On the other side, reporter lines such as ScxGFP

Table 2. Conditional Knockout and Reporter Mouse Models

\begin{tabular}{|c|c|c|c|}
\hline Mouse model & Mouse line & Description (what was the line used for?) & Reference \\
\hline Reporter & ScxGFP & $\begin{array}{l}\text { Allowed the identification of Scx-expression sites and the study of tendon/ } \\
\text { ligament lineage. }\end{array}$ & [95] \\
\hline Reporter & ScxAP & $\begin{array}{l}\text { Reporter line facilitates the identification of tendon cells and phenotypic } \\
\text { analysis in a wide range of genetic backgrounds }\end{array}$ & [95] \\
\hline Conditional & $\begin{array}{l}\text { ScxCre-L } \\
\text { ScxCre-H }\end{array}$ & $\begin{array}{l}\text { Transgenic mouse lines were used for targeting genes specifically in the } \\
\text { Scx-expressing domain. }\end{array}$ & [66] \\
\hline Conditional & $\mathrm{Scx}^{\mathrm{Cre} / \mathrm{Cre}} \mathrm{KI}$ & $\begin{array}{l}\text { Mouse line was used to identify that Scleraxis is transiently needed for } \\
\text { proper tissue maturation and integration of musculoskeletal components. }\end{array}$ & [148] \\
\hline Reporter & Col1a1GFP & $\begin{array}{l}\text { Reporter mice were used for the identification of a cell subpopulation at } \\
\text { different stages of skeletogenesis. }\end{array}$ & {$[149,150]$} \\
\hline Conditional & Col5a $1^{\text {flox/flox }}$ & $\begin{array}{l}\text { Mice strain was crossed with ScxCre transgenic mice for the generation of } \\
\text { a tendon and ligament-specific collagen V-null mice. }\end{array}$ & [151] \\
\hline Reporter & Nes-GFP & $\begin{array}{l}\text { GFP expression was used to isolate a subpopulation of nestin }{ }^{+} \text {TSPCs. } \\
\text { After single-cell analysis, gene expression profiles revealed that nestin } \\
\text { expression was activated at specific stages of tendon development. } \\
\text { Isolated nestin }{ }^{+} \text {TSPCs showed superior tenogenic capacity. }\end{array}$ & [152] \\
\hline Conditional & $\begin{array}{l}\operatorname{Dcn}{ }^{\text {flox/flox }} / \\
\text { Bgn }^{\text {flox/flox }}\end{array}$ & $\begin{array}{l}\text { Used to study the role of both proteoglycans in mature tendons. Tendons } \\
\text { showed alterations in collagen fibril structure, realignment, } \\
\text { and mechanical properties. }\end{array}$ & [153] \\
\hline
\end{tabular}


[95] have already helped to decipher the pivotal role of the master transcription factor Scleraxis for tenogenesis and tenogenic differentiation. Following this example, it would be of importance to continue the efforts generating transgenic $\mathrm{KO}$ mouse models that mimic mutations and diseases observed in humans and to improve our understanding on the molecular mechanisms behind such conditions.

The most important and remaining challenge in the field is related to finding specific tendon markers at each developmental stage. This knowledge would not only contribute to the obtention of valuable information but also opens the possibility for the production and generation of drugs that could "boost" tendon healing.

\section{Acknowledgments}

M.DC. and D.D. acknowledge the German Research Foundation (DFG grant DO1414/3-1) for the support of tendon research. We thank Dr. Girish Pattappa for English proof reading.

\section{Author Disclosure Statement}

No competing financial interests exist.

\section{References}

1. Brent AE, T Braun and CJ Tabin. (2005). Genetic analysis of interactions between the somitic muscle, cartilage and tendon cell lineages during mouse development. Development 132:515-528.

2. Cserjesi P, D Brown, KL Ligon, GE Lyons, NG Copeland, DJ Gilbert, NA Jenkins and EN Olson. (1995). Scleraxis: a basic helix-loop-helix protein that prefigures skeletal formation during mouse embryogenesis. Development 121: 1099-1110.

3. Schweitzer R, JH Chyung, LC Murtaugh, AE Brent, V Rosen, A Olson, A Lassar and CJ Tabin. (2001). Analysis of the tendon cell fate using Scleraxis, a specific marker for tendons and ligaments. Development 128:3855-3866.

4. Brent AE, R Schweitzer and CJ Tabin. (2003). A somitic compartment of tendon progenitors. Cell 113:235-248.

5. Brent AE and CJ Tabin. (2002). Developmental regulation of somite derivatives: muscle, cartilage and tendon. Curr Opin Genet Dev 12:548-557.

6. Dubrulle J and O Pourquie. (2003). Welcome to syndetome: a new somitic compartment. Dev Cell 4:611-612.

7. Tozer S and D Duprez. (2005). Tendon and ligament: development, repair and disease. Birth Defects Res C Embryo Today 75:226-236.

8. Murchison ND, BA Price, DA Conner, DR Keene, CJ Olson, CJ Tabin and R Schweitzer. (2007). Regulation of tendon differentiation by scleraxis distinguishes forcetransmitting tendons from muscle-anchoring tendons. Development 134:2697-2708.

9. Brent AE and CJ Tabin. (2004). FGF acts directly on the somitic tendon progenitors through the Ets transcription factors Pea3 and Erm to regulate scleraxis expression. Development 131:3885-3896.

10. Liu H, S Zhu, C Zhang, P Lu, J Hu, Z Yin, Y Ma, X Chen and $\mathrm{H}$ OuYang. (2014). Crucial transcription factors in tendon development and differentiation: their potential for tendon regeneration. Cell Tissue Res 356:287-298.
11. Docheva D, EB Hunziker, R Fassler and O Brandau. (2005). Tenomodulin is necessary for tenocyte proliferation and tendon maturation. Mol Cell Biol 25:699-705.

12. Alberton P, S Dex, C Popov, C Shukunami, M Schieker and D Docheva. (2015). Loss of tenomodulin results in reduced self-renewal and augmented senescence of tendon stem/progenitor cells. Stem Cells Dev 24:597-609.

13. Dex S, P Alberton, L Willkomm, T Söllradl, S Bago, S Milz, M Shakibaei, A Ignatius, W Bloch, et al. (2017). Tenomodulin is required for tendon endurance running and collagen I fibril adaptation to mechanical load. EBioMedicine 20:240-254.

14. Chevallier A, M Kieny and A Mauger. (1977). Limbsomite relationship: origin of the limb musculature. J Embryol Exp Morphol 41:245-258.

15. Edom-Vovard F and D Duprez. (2004). Signals regulating tendon formation during chick embryonic development. Dev Dyn 229:449-457.

16. Kuo CK, BC Petersen and RS Tuan. (2008). Spatiotemporal protein distribution of TGF-betas, their receptors, and extracellular matrix molecules during embryonic tendon development. Dev Dyn 237:1477-1489.

17. Pryce BA, SS Watson, ND Murchison, N Staverosky, N Dünker and R Schweitzer. (2009). Recruitment and maintenance of tendon progenitors by TGFbeta signaling are essential for tendon formation. Development 136:1351-1361.

18. Hasson P. (2011). "Soft" tissue patterning: muscles and tendons of the limb take their form. Dev Dyn 240:1100-1107.

19. Havis E, M-A Bonnin, I Olivera-Martinez, N Nazaret, M Ruggiu, J Weibel, C Durand, M-J Guerquin, C BonodBidaud, et al. (2014). Transcriptomic analysis of mouse limb tendon cells during development. Development 141: 3683-3696.

20. Dunker N and K Krieglstein. (2002). Tgfbeta2 -/Tgfbeta3 -/- double knockout mice display severe midline fusion defects and early embryonic lethality. Anat Embryol 206:73-83.

21. Maeda T, T Sakabe, A Sunaga, K Sakai, AL Rivera, DR Keene, T Sasaki, E Stavnezer, J Iannotti, et al. (2011). Conversion of mechanical force into TGF- $\beta$-mediated biochemical signals. Curr Biol 21:933-941.

22. Xu PX, J Cheng, JA Epstein and RL Maas. (1997). Mouse Eya genes are expressed during limb tendon development and encode a transcriptional activation function. Proc Natl Acad Sci USA 94:11974-11979.

23. Bonnin M-A, C Laclef, R Blaise, S Eloy-Trinquet, $F$ Relaix, P Maire and D Duprez. (2005). Six1 is not involved in limb tendon development, but is expressed in limb connective tissue under Shh regulation. Mech Dev 122:573-585.

24. Liu H, J Xu, C-F Liu, Y Lan, C Wylie and R Jiang. (2015). Whole transcriptome expression profiling of mouse limb tendon development by using RNA-seq. J Orthop Res 33: 840-848.

25. Nourissat G, F Berenbaum and D Duprez. (2015). Tendon injury: from biology to tendon repair. Nat Rev Rheumatol 11:223-233.

26. Wu M, DS Melichian, $M$ de La Garza, K Gruner, S Bhattacharyya, L Barr, A Nair, S Shahrara, PHS Sporn, et al. (2009). Essential roles for early growth response transcription factor Egr-1 in tissue fibrosis and wound healing. Am J Pathol 175:1041-1055.

27. Guerquin M-J, B Charvet, G Nourissat, E Havis, O Ronsin, M-A Bonnin, M Ruggiu, I Olivera-Martinez, N Robert, et al. (2013). Transcription factor EGR1 directs 
tendon differentiation and promotes tendon repair. J Clin Invest 123:3564-3576.

28. Lejard V, F Blais, M-J Guerquin, A Bonnet, M-A Bonnin, E Havis, M Malbouyres, CB Bidaud, G Maro, et al. (2011). EGR1 and EGR2 involvement in vertebrate tendon differentiation. J Biol Chem 286:5855-5867.

29. Screen HRC, DE Berk, KE Kadler, F Ramirez and MF Young. (2015). Tendon functional extracellular matrix. J Orthop Res 33:793-799.

30. KER R. (2007). Mechanics of tendon, from an engineering perspective. Int J Fatigue 29:1001-1009.

31. Shepherd JH, K Legerlotz, T Demirci, C Klemt, GP Riley and HRC Screen. (2014). Functionally distinct tendon fascicles exhibit different creep and stress relaxation behaviour. Proc Inst Mech Eng H 228:49-59.

32. Godinho MSC, CT Thorpe, SE Greenwald and HRC Screen. (2017). Elastin is localised to the interfascicular matrix of energy storing tendons and becomes increasingly disorganised with ageing. Sci Rep 7:9713.

33. Kjaer M. (2004). Role of extracellular matrix in adaptation of tendon and skeletal muscle to mechanical loading. Physiol Rev 84:649-698.

34. Thorpe CT, HL Birch, PD Clegg and HRC Screen. (2013). The role of the non-collagenous matrix in tendon function. Int J Exp Pathol 94:248-259.

35. Banos CC, AH Thomas and CK Kuo. (2008). Collagen fibrillogenesis in tendon development: current models and regulation of fibril assembly. Birth Defects Res. C Embryo Today 84:228-244.

36. Kannus P. (2000). Structure of the tendon connective tissue. Scand J Med Sci Sports 10:312-320.

37. Starborg T, Y Lu, KE Kadler and DF Holmes. (2008). Electron microscopy of collagen fibril structure in vitro and in vivo including three-dimensional reconstruction. Methods Cell Biol 88:319-345.

38. Kjaer M, H Langberg, K Heinemeier, ML Bayer, M Hansen, L Holm, S Doessing, M Kongsgaard, MR Krogsgaard and SP Magnusson. (2009). From mechanical loading to collagen synthesis, structural changes and function in human tendon. Scand J Med Sci Sports 19:500-510.

39. Lui PPY. (2015). Stem cell technology for tendon regeneration: current status, challenges, and future research directions. Stem Cells Cloning Adv Appl 8:163-174.

40. Voleti PB, MR Buckley and LJ Soslowsky. (2012). Tendon healing: repair and regeneration. Annu Rev Biomed Eng 14:47-71.

41. Docheva D, SA Müller, M Majewski and $\mathrm{CH}$ Evans. (2015). Biologics for tendon repair. Adv Drug Deliv Rev 84:222-239.

42. Thorpe CT, CP Udeze, HL Birch, PD Clegg and HRC Screen. (2012). Specialization of tendon mechanical properties results from interfascicular differences. J R Soc Interface 9:3108-3117.

43. Evans MJ and MH Kaufman. (1981). Establishment in culture of pluripotential cells from mouse embryos. Nature 292:154-156.

44. Capecchi M. (1989). Altering the genome by homologous recombination. Science 244:1288-1292.

45. Smithies O, RG Gregg, SS Boggs, MA Koralewski and RS Kucherlapati. (1985). Insertion of DNA sequences into the human chromosomal beta-globin locus by homologous recombination. Nature 317:230-234.

46. Koller BH, P Marrack, JW Kappler and O Smithies. (1990). Normal development of mice deficient in beta 2M,
MHC class I proteins, and CD8+ T cells. Science 248: 1227-1230.

47. Zijlstra M, M Bix, NE Simister, JM Loring, DH Raulet and R Jaenisch. (1990). Beta 2-microglobulin deficient mice lack CD4-8+ cytolytic T cells. Nature 344:742-746.

48. Capecchi MR. (1994). Targeted gene replacement. Sci Am 270:52-59.

49. Austin CP, JF Battey, A Bradley, M Bucan, M Capecchi, FS Collins, WF Dove, G Duyk, S Dymecki, et al. (2004). The knockout mouse project. Nat Genet 36:921-924.

50. Doyle A, MP McGarry, NA Lee and JJ Lee. (2012). The construction of transgenic and gene knockout/knockin mouse models of human disease. Transgenic Res 21:327-349.

51. Guan C, C Ye, X Yang and J Gao. (2010). A review of current large-scale mouse knockout efforts. Genesis 48:73-85.

52. Bouabe $\mathrm{H}$ and K Okkenhaug. (2013). Gene targeting in mice: a review. Methods Mol Biol 1064:315-336.

53. Cong L, FA Ran, D Cox, S Lin, R Barretto, N Habib, PD Hsu, X Wu, W Jiang, LA Marraffini and F Zhang. (2013). Multiplex genome engineering using CRISPR/Cas systems. Science 339:819-823.

54. Abudayyeh OO, JS Gootenberg, P Essletzbichler, S Han, J Joung, JJ Belanto, V Verdine, DBT Cox, MJ Kellner, et al. (2017). RNA targeting with CRISPR-Cas13. Nature 550: 280-284.

55. Kothary R, S Clapoff, A Brown, R Campbell, A Peterson and J Rossant. (1988). A transgene containing lacZ inserted into the dystonia locus is expressed in neural tube. Nature 335:435-437.

56. Abuin A, GM Hansen and B Zambrowicz. (2007). Gene trap mutagenesis. Handb Exp Pharmacol 178:129-147.

57. Gossler A, AL Joyner, J Rossant and WC Skarnes. (1989). Mouse embryonic stem cells and reporter constructs to detect developmentally regulated genes. Science 244:463-465.

58. Hall B, A Limaye and AB Kulkarni. (2009). Overview: Generation of gene knockout mice. Curr Protoc Cell Biol. Chapter 19:Unit 19.12 19.12. 1-17.

59. Capecchi MR. (2005). Gene targeting in mice: functional analysis of the mammalian genome for the twenty-first century. Nat Rev Genet 6:507-512.

60. Eisener-Dorman AF, DA Lawrence and VJ Bolivar. (2009). Cautionary insights on knockout mouse studies: the gene or not the gene? Brain Behav Immun 23:318-324.

61. Potter H and R Heller. (2017). Transfection by Electroporation. Curr Protoc Immunol 117:15.1-10.15.9.

62. Dickinson ME, AM Flenniken, X Ji, L Teboul, MD Wong, JK White, TF Meehan, WJ Weninger, H Westerberg, et al. (2016). High-throughput discovery of novel developmental phenotypes. Nature 537:508-514.

63. Logan M, JF Martin, A Nagy, C Lobe, EN Olson and CJ Tabin. (2002). Expression of Cre Recombinase in the developing mouse limb bud driven by a Prxl enhancer. Genesis 33:77-80.

64. Senecoff JF, PJ Rossmeissl and MM Cox. (1988). DNA recognition by the FLP recombinase of the yeast $2 \mathrm{mu}$ plasmid. A mutational analysis of the FLP binding site. $\mathrm{J}$ Mol Biol 201:405-421.

65. Deng C and MR Capecchi. (1992). Reexamination of gene targeting frequency as a function of the extent of homology between the targeting vector and the target locus. Mol Cell Biol 12:3365-3371.

66. Sugimoto Y, A Takimoto, Y Hiraki and C Shukunami. (2013). Generation and characterization of ScxCre transgenic mice. Genesis 51:275-283. 
67. Gu H, JD Marth, PC Orban, H Mossmann and K Rajewsky. (1994). Deletion of a DNA polymerase beta gene segment in T cells using cell type-specific gene targeting. Science 265:103-106.

68. Zhang J, J Zhao, W-j Jiang, X-w Shan, X-m Yang and J-g Gao. (2012). Conditional gene manipulation: cre-ating a new biological era. J Zhejiang Univ Sci B 13:511-524.

69. Heffner CS, CH Pratt, RP Babiuk, Y Sharma, SF Rockwood, LR Donahue, JT Eppig and SA Murray. (2012). Supporting conditional mouse mutagenesis with a comprehensive cre characterization resource. Nat Commun 3:1218.

70. Gossen M and H Bujard. (1992). Tight control of gene expression in mammalian cells by tetracycline-responsive promoters. Proc Natl Acad Sci USA 89:5547-5551.

71. Gossen M, S Freundlieb, G Bender, G Muller, W Hillen and $\mathrm{H}$ Bujard. (1995). Transcriptional activation by tetracyclines in mammalian cells. Science 268:1766-1769.

72. Metzger D, J Clifford, H Chiba and P Chambon. (1995). Conditional site-specific recombination in mammalian cells using a ligand-dependent chimeric Cre recombinase. Proc Natl Acad Sci USA 92:6991-6995.

73. Saunders TL. (2011). Inducible transgenic mouse models. Methods Mol Biol 693:103-115.

74. DeMayo FJ and SY Tsai. (2001). Targeted gene regulation and gene ablation. Trends Endocrinol Metab 12:348-353.

75. Nelson CE, CH Hakim, DG Ousterout, PI Thakore, EA Moreb, RM Castellanos Rivera, S Madhavan, X Pan, FA Ran, et al. (2016). In vivo genome editing improves muscle function in a mouse model of Duchenne muscular dystrophy. Science 351:403-407.

76. Tabebordbar M, K Zhu, JKW Cheng, WL Chew, JJ Widrick, WX Yan, C Maesner, EY Wu, R Xiao, et al. (2016). In vivo gene editing in dystrophic mouse muscle and muscle stem cells. Science 351:407-411.

77. Suzuki H, Y Ito, M Shinohara, S Yamashita, S Ichinose, A Kishida, T Oyaizu, T Kayama, R Nakamichi, et al. (2016). Gene targeting of the transcription factor Mohawk in rats causes heterotopic ossification of Achilles tendon via failed tenogenesis. Proc Natl Acad Sci USA 113:7840-7845.

78. Peng R, G Lin and J Li. (2016). Potential pitfalls of CRISPR/Cas9-mediated genome editing. FEBS J 283: 1218-1231.

79. Kaplan FS, M Xu, P Seemann, JM Connor, DL Glaser, L Carroll, P Delai, E Fastnacht-Urban, SJ Forman, et al. (2009). Classic and atypical fibrodysplasia ossificans progressiva (FOP) phenotypes are caused by mutations in the bone morphogenetic protein (BMP) type I receptor ACVR1. Hum Mutat 30:379-390.

80. Gregson CL, P Hollingworth, M Williams, KA Petrie, AN Bullock, MA Brown, JH Tobias and JT Triffitt. (2011). A novel ACVR1 mutation in the glycine/serine-rich domain found in the most benign case of a fibrodysplasia ossificans progressiva variant reported to date. Bone 48:654-658.

81. Chakkalakal SA, D Zhang, AL Culbert, MR Convente, RJ Caron, AC Wright, ADA Maidment, FS Kaplan and EM Shore. (2012). An Acvr1 R206H knock-in mouse has fibrodysplasia ossificans progressiva.J Bone Miner Res 27: 1746-1756.

82. Convente MR, SA Chakkalakal, E Yang, RJ Caron, D Zhang, T Kambayashi, FS Kaplan and EM Shore. (2017). Depletion of mast cells and macrophages impairs heterotopic ossification in an Acvr1R206H mouse model of fibrodysplasia ossificans progressiva. J Bone Miner Res 33: 269-282.
83. Kilts T, L Ameye, F Syed-Picard, M Ono, AD Berendsen, A Oldberg, A-M Heegaard, Y Bi and MF Young. (2009). Potential roles for the small leucine-rich proteoglycans biglycan and fibromodulin in ectopic ossification of tendon induced by exercise and in modulating rotarod performance. Scand J Med Sci Sports 19:536-546.

84. Geerkens C, U Vetter, W Just, NS Fedarko, LW Fisher, MF Young, JD Termine, PG Robey, D Wöhrle and W Vogel. (1995). The X-chromosomal human biglycan gene BGN is subject to $\mathrm{X}$ inactivation but is transcribed like an X-Y homologous gene. Hum Genet 96:44-52.

85. Chen X-D, S Shi, T Xu, PG Robey and MF Young. (2002). Age-related osteoporosis in biglycan-deficient mice is related to defects in bone marrow stromal cells. J Bone Miner Res 17:331-340.

86. Corsi A, T Xu, XD Chen, A Boyde, J Liang, M Mankani, B Sommer, RV Iozzo, I Eichstetter, et al. (2002). Phenotypic effects of biglycan deficiency are linked to collagen fibril abnormalities, are synergized by decorin deficiency, and mimic Ehlers-Danlos-like changes in bone and other connective tissues. J Bone Miner Res 17:1180-1189.

87. Chen X-D, LW Fisher, PG Robey and MF Young. (2004). The small leucine-rich proteoglycan biglycan modulates BMP-4-induced osteoblast differentiation. FASEB J 18: 948-958.

88. Bi Y, D Ehirchiou, TM Kilts, CA Inkson, MC Embree, W Sonoyama, L Li, AI Leet, B-M Seo, et al. (2007). Identification of tendon stem/progenitor cells and the role of the extracellular matrix in their niche. Nat Med 13:1219-1227.

89. Butler DL, N Juncosa and MR Dressler. (2004). Functional efficacy of tendon repair processes. Annu Rev Biomed Eng 6:303-329.

90. Lin D, P Alberton, MD Caceres, E Volkmer, M Schieker and D Docheva. (2017). Tenomodulin is essential for prevention of adipocyte accumulation and fibrovascular scar formation during early tendon healing. Cell Death Dis 8:e3116.

91. Bell R, P Taub, P Cagle, EL Flatow and N AndarawisPuri. (2015). Development of a mouse model of supraspinatus tendon insertion site healing. J Orthop Res 33:25-32.

92. Yang G, BB Rothrauff and RS Tuan. (2013). Tendon and ligament regeneration and repair: clinical relevance and developmental paradigm. Birth Defects Res C Embryo Today 99:203-222.

93. Lewandoski M. (2001). Conditional control of gene expression in the mouse. Nat Rev Genet 2:743-755.

94. Thyagarajan B, MJ Guimarães, AC Groth and MP Calos. (2000). Mammalian genomes contain active recombinase recognition sites. Gene 244:47-54.

95. Pryce BA, AE Brent, ND Murchison, CJ Tabin and R Schweitzer. (2007). Generation of transgenic tendon reporters, ScxGFP and ScxAP, using regulatory elements of the scleraxis gene. Dev Dyn 236:1677-1682.

96. Gordon JA, BR Freedman, A Zuskov, RV Iozzo, DE Birk and LJ Soslowsky. (2015). Achilles tendons from decorinand biglycan-null mouse models have inferior mechanical and structural properties predicted by an image-based empirical damage model. J Biomech 48:2110-2115.

97. Buckley MR, GR Huffman, RV Iozzo, DE Birk and LJ Soslowsky. (2013). The location-specific role of proteoglycans in the flexor carpi ulnaris tendon. Connect Tissue Res 54:367-373.

98. Dunkman AA, MR Buckley, MJ Mienaltowski, SM Adams, SJ Thomas, L Satchell, A Kumar, L Pathmanathan, 
DP Beason, et al. (2014). The tendon injury response is influenced by decorin and biglycan. Ann Biomed Eng 42: 619-630.

99. Dunkman AA, MR Buckley, MJ Mienaltowski, SM Adams, SJ Thomas, A Kumar, DP Beason, RV Iozzo, DE Birk and LJ Soslowsky. (2014). The injury response of aged tendons in the absence of biglycan and decorin. Matrix Biol 35:232-238.

100. Dourte LM, L Pathmanathan, MJ Mienaltowski, AF Jawad, DE Birk and LJ Soslowsky. (2013). Mechanical, compositional, and structural properties of the mouse patellar tendon with changes in biglycan gene expression. J Orthop Res 31:1430-1437.

101. Yoon JH and J Halper. (2005). Tendon proteoglycans: biochemistry and function. J Musculoskelet Neuronal Interact 5:22-34.

102. Zelzer E, E Blitz, ML Killian and S Thomopoulos. (2014). Tendon-to-bone attachment: from development to maturity. Birth Defects Res C Embryo Today 102:101-112.

103. Blitz E, S Viukov, A Sharir, Y Shwartz, JL Galloway, BA Pryce, RL Johnson, CJ Tabin, R Schweitzer and E Zelzer. (2009). Bone ridge patterning during musculoskeletal assembly is mediated through SCX regulation of Bmp4 at the tendon-skeleton junction. Dev Cell 17:861-873.

104. Lohler J, R Timpl and R Jaenisch. (1984). Embryonic lethal mutation in mouse collagen I gene causes rupture of blood vessels and is associated with erythropoietic and mesenchymal cell death. Cell 38:597-607.

105. Mao JR and J Bristow. (2001). The Ehlers-Danlos syndrome: on beyond collagens. J Clin Invest 107:1063-1069.

106. Uitto J and F Ringpfeil. (2004). Ehlers-Danlos syndromemolecular genetics beyond the collagens. J Invest Dermatol 122:xii-xiii.

107. Nuytinck L, M Freund, L Lagae, GE Pierard, T Hermanns-Le and A de Paepe. (2000). Classical EhlersDanlos syndrome caused by a mutation in type I collagen. Am J Hum Genet 66:1398-1402.

108. Liu X, H Wu, M Byrne, J Jeffrey, S Krane and R Jaenisch. (1995). A targeted mutation at the known collagenase cleavage site in mouse type I collagen impairs tissue remodeling. J Cell Biol 130:227-237.

109. Chen F, R Guo, S Itoh, L Moreno, E Rosenthal, T Zappitelli, RA Zirngibl, A Flenniken, W Cole, et al. (2014). First mouse model for combined osteogenesis imperfecta and Ehlers-Danlos syndrome. J Bone Miner Res 29:1412-1423.

110. DiCesare P, N Hauser, D Lehman, S Pasumarti and M Paulsson. (1994). Cartilage oligomeric matrix protein (COMP) is an abundant component of tendon. FEBS Lett 354:237-240.

111. Smith RK, L Zunino, PM Webbon and D Heinegard. (1997). The distribution of cartilage oligomeric matrix protein (COMP) in tendon and its variation with tendon site, age and load. Matrix Biol 16:255-271.

112. Svensson L, A Aszodi, D Heinegard, EB Hunziker, FP Reinholt, R Fassler and A Oldberg. (2002). Cartilage oligomeric matrix protein-deficient mice have normal skeletal development. Mol Cell Biol 22:4366-4371.

113. Dourte LM, L Pathmanathan, AF Jawad, RV Iozzo, MJ Mienaltowski, DE Birk and LJ Soslowsky. (2012). Influence of decorin on the mechanical, compositional, and structural properties of the mouse patellar tendon. J Biomech Eng 134:31005.

114. Zhang G, Y Ezura, I Chervoneva, PS Robinson, DP Beason, LJ Carine, RV Soslowsky, RV Iozzo and DE
Birk. (2006). Decorin regulates assembly of collagen fibrils and acquisition of biomechanical properties during tendon development. J Cell Biochem 98:1436-1449.

115. Hakkinen L, S Strassburger, VM Kahari, PG Scott, I Eichstetter, RV Lozzo and H Larjava. (2000). A role for decorin in the structural organization of periodontal ligament. Lab Invest 80:1869-1880.

116. Frizziero A, F Vittadini, G Gasparre and S Masiero. (2014). Impact of oestrogen deficiency and aging on tendon: concise review. Muscles Ligaments Tendons J 4:324-328.

117. Giusti B and G Pepe. (2016). Fibrillins in Tendon. Front Aging Neurosci 8:237.

118. Boregowda R, E Paul, J White and TM Ritty. (2008). Bone and soft connective tissue alterations result from loss of fibrillin-2 expression. Matrix Biol 27:661-666.

119. Majava M, PN Bishop, P Hagg, PG Scott, A Rice, C Inglehearn, CJ Hammond, TD Spector, L Ala-Kokko and M Mannikko. (2007). Novel mutations in the small leucine-rich repeat protein/proteoglycan (SLRP) genes in high myopia. Hum Mutat 28:336-344.

120. Ezura Y, S Chakravarti, A Oldberg, I Chervoneva and DE Birk. (2000). Differential expression of lumican and fibromodulin regulate collagen fibrillogenesis in developing mouse tendons. J Cell Biol 151:779-788.

121. Jepsen KJ, F Wu, JH Peragallo, J Paul, L Roberts, Y Ezura, A Oldberg, DE Birk and S Chakravarti. (2002). A syndrome of joint laxity and impaired tendon integrity in lumican- and fibromodulin-deficient mice. J Biol Chem 277:35532-35540.

122. Svensson L, A Aszodi, FP Reinholt, R Fassler, D Heinegard and A Oldberg. (1999). Fibromodulin-null mice have abnormal collagen fibrils, tissue organization, and altered lumican deposition in tendon. J Biol Chem 274:9636-9647.

123. Mendias CL, KI Bakhurin and JA Faulkner. (2008). Tendons of myostatin-deficient mice are small, brittle, and hypocellular. Proc Natl Acad Sci USA 105:388-393.

124. Mikic B, BJ Schalet, RT Clark, V Gaschen and EB Hunziker. (2001). GDF-5 deficiency in mice alters the ultrastructure, mechanical properties and composition of the Achilles tendon. J Orthop Res 19:365-371.

125. Mikic B. (2004). Multiple effects of GDF-5 deficiency on skeletal tissues: implications for therapeutic bioengineering. Ann Biomed Eng 32:466-476.

126. Fassler R and M Meyer. (1995). Consequences of lack of beta 1 integrin gene expression in mice. Genes Dev 9: 1896-1908.

127. Stephens LE, AE Sutherland, IV Klimanskaya, A Andrieux, J Meneses, RA Pedersen and CH Damsky. (1995). Deletion of beta 1 integrins in mice results in inner cell mass failure and peri-implantation lethality. Genes Dev 9: 1883-1895.

128. Popova SN, M Barczyk, C-F Tiger, W Beertsen, P Zigrino, A Aszodi, N Miosge, E Forsberg and D Gullberg. (2007). Alpha11 beta1 integrin-dependent regulation of periodontal ligament function in the erupting mouse incisor. Mol Cell Biol 27:4306-4316.

129. Popova SN, B Rodriguez-Sánchez, A Lidén, C Betsholtz, $T$ van den Bos and D Gullberg. (2004). The mesenchymal alpha11beta1 integrin attenuates PDGF-BB-stimulated chemotaxis of embryonic fibroblasts on collagens. Dev Biol 270:427-442.

130. Eliasson P, T Andersson, J Kulas, P Seemann and P Aspenberg. (2009). Myostatin in tendon maintenance and repair. Growth Factors 27:247-254. 
131. Ito Y, N Toriuchi, $\mathrm{T}$ Yoshitaka, H Ueno-Kudoh, T Sato, $\mathrm{S}$ Yokoyama, K Nishida, T Akimoto, $\mathrm{M}$ Takahashi, $\mathrm{S}$ Miyaki and H Asahara. (2010). The Mohawk homeobox gene is a critical regulator of tendon differentiation. Proc Natl Acad Sci USA 107:10538-10542.

132. Onizuka N, Y Ito, M Inagawa, H Nakahara, S Takada, M Lotz, Y Toyama and H Asahara. (2014). The Mohawk homeobox transcription factor regulates the differentiation of tendons and volar plates. J Orthop Sci 19:172-180.

133. Liu W, SS Watson, Y Lan, DR Keene, CE Ovitt, H Liu, R Schweitzer and R Jiang. (2010). The atypical homeodomain transcription factor Mohawk controls tendon morphogenesis. Mol Cell Biol 30:4797-4807.

134. Koda N, T Sato, M Shinohara, S Ichinose, Y Ito, R Nakamichi, T Kayama, K Kataoka, H Suzuki, K Moriyama and H Asahara. (2017). The transcription factor mohawk homeobox regulates homeostasis of the periodontal ligament. Development 144:313-320.

135. Bagchi RA, P Roche, N Aroutiounova, L Espira, B Abrenica, R Schweitzer and MP Czubryt. (2016). The transcription factor scleraxis is a critical regulator of cardiac fibroblast phenotype. BMC Biol 14:21.

136. Wang L, CS Bresee, H Jiang, W He, T Ren, R Schweitzer and JV Brigande. (2011). Scleraxis is required for differentiation of the stapedius and tensor tympani tendons of the middle ear. J Assoc Res Otolaryngol 12:407-421.

137. Huang AH, HH Lu and R Schweitzer. (2015). Molecular regulation of tendon cell fate during development. J Orthop Res 33:800-812.

138. Senol-Cosar O, RJR Flach, M DiStefano, A Chawla, S Nicoloro, J Straubhaar, OT Hardy, HL Noh, JK Kim, et al. (2016). Tenomodulin promotes human adipocyte differentiation and beneficial visceral adipose tissue expansion. Nat Commun 7:10686.

139. Dex S, D Lin, C Shukunami and D Docheva. (2016). Tenogenic modulating insider factor: systematic assessment on the functions of tenomodulin gene. Gene 587:1-17.

140. Proetzel G, SA Pawlowski, MV Wiles, M Yin, GP Boivin, PN Howles, J Ding, MW Ferguson and T Doetschman. (1995). Transforming growth factor-beta 3 is required for secondary palate fusion. Nat Genet 11:409-414.

141. Sanford LP, I Ormsby, AC Gittenberger-de Groot, H Sariola, R Friedman, GP Boivin, EL Cardell and T Doetschman. (1997). TGFbeta2 knockout mice have multiple developmental defects that are non-overlapping with other TGFbeta knockout phenotypes. Development 124:2659 2670.

142. Kyriakides TR, YH Zhu, LT Smith, SD Bain, Z Yang, MT Lin, KG Danielson, RV Iozzo, M LaMarca, et al. (1998). Mice that lack thrombospondin 2 display connective tissue abnormalities that are associated with disordered collagen fibrillogenesis, an increased vascular density, and a bleeding diathesis. J Cell Biol 140:419-430.

143. Bornstein P, TR Kyriakides, Z Yang, LC Armstrong and DE Birk. (2000). Thrombospondin 2 modulates collagen fibrillogenesis and angiogenesis. J Invest Dermatol Symp Proc 5:61-66.

144. Frolova EG, J Drazba, I Krukovets, V Kostenko, L Blech, C Harry, A Vasanji, C Drumm, P Sul, et al. (2014). Control of organization and function of muscle and tendon by thrombospondin-4. Matrix Biol 37:35-48.

145. Cui J, E Randell, J Renouf, G Sun, R Green, F-Y Han and Y-G Xie. (2006). Thrombospondin-4 1186GC (A387P) is a sex-dependent risk factor for myocardial infarction: a large replication study with increased sample size from the same population. Am Heart J 152:543.e1-5435.

146. Cui J, E Randell, J Renouf, G Sun, F-Y Han, B Younghusband and Y-G Xie. (2004). Gender dependent association of thrombospondin-4 A387P polymorphism with myocardial infarction. Arterioscler Thromb Vasc Biol 24: e183-e184.

147. Frolova EG, E Pluskota, I Krukovets, T Burke, C Drumm, JD Smith, L Blech, M Febbraio, P Bornstein, EF Plow and OI Stenina. (2010). Thrombospondin-4 regulates vascular inflammation and atherogenesis. Circ Res 107:1313-1325.

148. Yoshimoto Y, A Takimoto, H Watanabe, Y Hiraki, G Kondoh and C Shukunami. (2017). Scleraxis is required for maturation of tissue domains for proper integration of the musculoskeletal system. Sci Rep 7:45010.

149. Kalajzic I, Z Kalajzic, M Kaliterna, G Gronowicz, SH Clark, AC Lichtler and D Rowe. (2002). Use of type I collagen green fluorescent protein transgenes to identify subpopulations of cells at different stages of the osteoblast lineage. J Bone Miner Res 17:15-25.

150. Balic A, HL Aguila and M Mina. (2010). Identification of cells at early and late stages of polarization during odontoblast differentiation using OBCol3.6GFP and OBCol2 .3GFP transgenic mice. Bone 47:948-958.

151. Sun M, BK Connizzo, SM Adams, BR Freedman, RJ Wenstrup, LJ Soslowsky and DE Birk. (2015). Targeted deletion of collagen $\mathrm{V}$ in tendons and ligaments results in a classic Ehlers-Danlos syndrome joint phenotype. Am J Pathol 185:1436-1447.

152. Yin Z, J-J Hu, L Yang, Z-F Zheng, C-R An, B-B Wu, C Zhang, W-L Shen, H-H Liu, et al. (2016). Single-cell analysis reveals a nestin+ tendon stem/progenitor cell population with strong tenogenic potentiality. Sci Adv 2:e1600874.

153. Robinson KA, M Sun, CE Barnum, SN Weiss, J Huegel, SS Shetye, L Lin, D Saez, SM Adams, et al. (2017). Decorin and biglycan are necessary for maintaining collagen fibril structure, fiber realignment, and mechanical properties of mature tendons. Matrix Biol 64:81-93.

154. Inducible Knockout Mouse | For time-dependent gene control $\mid$ genOway. www.genoway.com/services/customized-mouse/ knockout-models/conditional-ko-time.htm Accessed May 24, 2018.

155. Tissue-Specific Knockout Mouse | How to focus on one tissue | genOway. www.genoway.com/services/customized-mouse/ knockout-models/conditional-ko-tissue.htm Accessed May 24, 2018.

156. Constitutive Knockout Mouse | To get faster first results | genOway. www.genoway.com/services/customized-mouse/ knockout-models/constitutive-ko.htm Accessed May 24, 2018.

Address correspondence to: Prof. Denitsa Docheva Experimental Trauma Surgery Department of Trauma Surgery University Regensburg Medical Centre Franz-Josef-Strauss-Allee 11 Regensburg 93053 Germany

E-mail: denitsa.docheva@ukr.de

Received for publication June 7, 2018 Accepted after revision July 5, 2018

Prepublished on Liebert Instant Online July 6, 2018 